\title{
Commentary: The mental representation of integers: An abstract-to-concrete shift in the understanding of mathematical concepts
}

\author{
Melinda A. Mende ${ }^{1}$, Samuel Shaki ${ }^{2}$ and Martin H. Fischer ${ }^{1 *}$ \\ ${ }^{1}$ Division of Cognitive Sciences, Department of Psychology, University of Potsdam, Potsdam, Germany, ${ }^{2}$ Department of \\ Behavioral Sciences, Ariel University, Ariel, Israel
}

Keywords: cognitive development, mental number line, negative numbers, embodied cognition, abstract concepts

\section{A Commentary on}

The mental representation of integers: An abstract-to-concrete shift in the understanding of mathematical concepts

OPEN ACCESS

Edited by:

Frank Domahs,

Philipps University of Marburg,

Germany

Reviewed by:

Ken Hiraiwa

Meiji Gakuin University, Japan

Sashank Varma,

University of Minnesota, United States

Daniel L Schwartz,

Stanford University, United States

${ }^{*}$ Correspondence:

Martin H. Fischer

martinf@uni-potsdam.de

Specialty section: This article was submitted to

Developmental Psychology,

a section of the journal

Frontiers in Psychology

Received: 17 November 2017 Accepted: 07 February 2018

Published: 27 February 2018

Citation:

Mende MA, Shaki S and Fischer MH

(2018) Commentary: The mental

representation of integers: An

abstract-to-concrete shift in the

understanding of mathematical

concepts. Front. Psychol. 9:209.

doi: 10.3389/fpsyg.2018.00209 by Varma, S., and Schwartz, D. L. (2011). Cognition 121, 363-385. doi: 10.1016/j.cognition.2011.08. 005

Decision times during processing of positive number symbols (1, 2, 3 etc.) inform our understanding of mental representations of integers (Holyoak, 1978; Dehaene et al., 1993; Fischer and Shaki, 2014). Effects of number magnitude on cognition include distance effects (faster discrimination for larger numerical differences in a number pair), size effects (faster processing of smaller numbers), Spatial-Numerical Association of Response Codes (SNARC; faster left/right responses to small/large numbers), linguistic markedness (MARC; faster left/right responses to odd/even numbers) and semantic congruity effects (faster smaller/larger decisions over smaller/larger number pairs). Results converge on the notion of a spatially oriented mental number line (MNL) where numerically smaller number concepts exist to the left of larger number concepts. How do these performance signatures help us to understand the cognitive representation of negative number symbols $(-1,-2,-3$ etc.)? Unlike natural number symbols, negative number symbols lack corresponding real entities that support sensory-motor learning. We discuss a recent proposal by Varma and Schwartz (2011) with implications for developmental research.

\section{TERMINOLOGICAL CLARIFICATION}

Different terms distinguish two fundamentally different views regarding the cognitive representation of negative numbers: The first view states that negative numbers are cognitively represented to the left of positive numbers, thereby extending the MNL infinitely leftward (henceforth called "extended MNL account"). The second view states that negative numbers have no cognitive representations but are understood through augmenting positive entries of the MNL (henceforth called "rule-based MNL account"). This dichotomy reflects identical distinctions made by Fischer (2003: ontogenetic vs. phylogenetic), Shaki and Petrusic (2005: extended number line vs. magnitude polarity), Ganor-Stern and Tzelgov (2008: holistic vs. components) and Varma and Schwartz (2011: analog+ vs. symbol+). Evidence from magnitude comparisons was used to support either account (see Table 1 for more studies) so we review it before recommending methodological improvements. 


\section{EVIDENCE FROM MAGNITUDE COMPARISON}

Magnitude comparison was first used by Fischer (2003) to report a cognitive processing signature for negative numbers: Adults identified the larger of two digits ranging from -9 to +9 and shown in pairs with constant numerical distance (to control both distance and MARC effects). Faster decisions obtained when the spatial arrangement of digits on screen matched a leftwardextended mental number line, thus supporting the extended MNL account. However, Shaki and Petrusic (2005) identified a confound with semantic congruity and showed that results

TABLE 1 | Summary of previous empirical work on the cognitive representation of negative numbers.

\begin{tabular}{|c|c|c|c|c|}
\hline Task & Stimuli & Responses & Measures & References \\
\hline Magnitude comparison & Spatial & Spatial (discrete) & SNARC effect & Fischer, 2003 \\
\hline Magnitude comparison & Spatial & Spatial (discrete) & $\begin{array}{l}\text { SNARC + Semantic congruity } \\
\text { effect }\end{array}$ & $\begin{array}{l}\text { Shaki and } \\
\text { Petrusic, } 2005\end{array}$ \\
\hline Magnitude comparison & Spatial & Spatial (discrete) & $\begin{array}{l}\text { Distance effect }+ \text { Semantic } \\
\text { congruity effect }\end{array}$ & Ganor-Stern, 2012 \\
\hline Magnitude comparison & Spatial & Spatial (discrete) & $\begin{array}{l}\text { Distance effect }+ \text { Semantic } \\
\text { congruity effect }\end{array}$ & $\begin{array}{l}\text { Ganor-Stern et al., } \\
2010\end{array}$ \\
\hline Magnitude comparison & Spatial & Spatial (discrete) & $\begin{array}{l}\text { Semantic congruity effect }+ \text { Size } \\
\text { effect }\end{array}$ & $\begin{array}{l}\text { Ganor-Stern and } \\
\text { Tzelgov, } 2008\end{array}$ \\
\hline Magnitude comparison & Spatial & Spatial (discrete) & $\begin{array}{l}\text { Distance effect }+ \text { Semantic } \\
\text { congruity effect }\end{array}$ & $\begin{array}{l}\text { Tzelgov et al., } \\
2009\end{array}$ \\
\hline Magnitude comparison & Spatial & Spatial (discrete) & Sign-decade compatibility effect & Huber et al., 2015 \\
\hline Magnitude comparison & Spatial & Spatial (discrete) & $\begin{array}{l}\text { Distance effect }+ \text { Semantic } \\
\text { congruity effect }+ \text { Size effect }\end{array}$ & $\begin{array}{l}\text { Varma and } \\
\text { Schwartz, } 2011\end{array}$ \\
\hline Magnitude comparison & Spatial & Spatial (discrete) & (Neural) Distance effect (fMRI) & Blair et al., 2012 \\
\hline Magnitude comparison & Spatial & Spatial (discrete) & (Neural) Distance effect (fMRI) & $\begin{array}{l}\text { Gullick et al., } \\
\text { 2012; Gullick and } \\
\text { Wolford, } 2013\end{array}$ \\
\hline Physical comparison & Spatial & Spatial (discrete) & $\begin{array}{l}\text { Distance effect }+ \text { Size Congruity } \\
\text { Effect }\end{array}$ & $\begin{array}{l}\text { Tzelgov et al., } \\
2009\end{array}$ \\
\hline Physical comparison & Spatial & Spatial (discrete) & Congruity Effect (ERP) & Parnes et al., 2012 \\
\hline Magnitude comparison & Spatial & Spatial (discrete) & Number mining (fMRI) & $\begin{array}{l}\text { Chassy and } \\
\text { Grodd, } 2012\end{array}$ \\
\hline Magnitude classification & Centered & Spatial (discrete) & Distance effect + SNARC & $\begin{array}{l}\text { Krajcsi and lgács, } \\
2010\end{array}$ \\
\hline Magnitude classification & Centered & Spatial (discrete) & SNARC effect & $\begin{array}{l}\text { Fischer and } \\
\text { Rottmann, (2005, } \\
\text { Experiment 2) }\end{array}$ \\
\hline Parity classification + Priming & Centered & Spatial (discrete) & SNARC effect & $\begin{array}{l}\text { Tse and Altarriba, } \\
2010\end{array}$ \\
\hline Parity classification & Centered & Spatial (discrete) & SNARC effect & $\begin{array}{l}\text { Fischer and } \\
\text { Rottmann (2005, } \\
\text { Experiment 1) }\end{array}$ \\
\hline Parity classification & Centered & Spatial (discrete) & SNARC effect & Nuerk et al., 2004 \\
\hline Parity classification & Centered & Spatial (discrete) & SNARC effect & $\begin{array}{l}\text { Prather and } \\
\text { Boroditsky, } 2003\end{array}$ \\
\hline Pointing (Number line) & Centered & Spatial (continuous) & Scalar variability model & $\begin{array}{l}\text { Ganor-Stern and } \\
\text { Tzelgov, } 2008\end{array}$ \\
\hline Pointing (Number line) & Centered & Spatial (continuous) & Linear or logarithmic & $\begin{array}{l}\text { Young and Booth, } \\
2015\end{array}$ \\
\hline Center Classification (Number line) & Spatial & Verbal & Leftward bias, SNARC effect & $\begin{array}{l}\text { Loftus et al. (2009, } \\
\text { Experiment 2) }\end{array}$ \\
\hline Detection (visual) & Centered digit + Spatial target & Centered & Spatial shift of attention & Dodd, 2011 \\
\hline Detection (visual) & Centered digit + Spatial target & Centered & Spatial shift of attention & $\begin{array}{l}\text { Zhang and You, } \\
2012\end{array}$ \\
\hline Detection (auditory) & Centered digit + Spatial target & Centered & Spatial shift of attention & Kong et al., 2012 \\
\hline
\end{tabular}


depend on whether positive and negative numbers are blocked or mixed.

Ganor-Stern and Tzelgov (2008) found similar size effects for positive and negative numbers in the comparison task and a systematic decrease of localization variability with increasing number magnitude in a number-to-position task (where adults localized the position of numbers with a mouse cursor on a horizontal line). They inferred a rule-based MNL account.

Varma and Schwartz (2011) found an inverse distance effect in magnitude comparison with adults, inconsistent with a rulebased MNL which predicted no distance effect at all in mixed comparisons (with one positive and one negative integer), due to superficial sign comparisons. The authors augmented the extended MNL account by postulating additional knowledge about the relationship between positive and negative number concepts which is not available yet to 6th graders because they showed no inverse distance effect and thus used a rule-based MNL.

\section{EVIDENCE FROM OTHER METHODS}

This conclusion is surprising, given the wide consensus for a concrete-to-abstract shift in knowledge development. Why are conclusions so heterogeneous, even when using a single task? Other methods assessed negative number representation, including pointing, parity judgments, brain activation, eye movement recording and computer simulation (see Table 1 for details). For example, Gullick and Wolford (2013) investigated neural distance effects in children. They found that IPS activity increased with age while parietal, frontal and precentral activity decreased, consistent with an anterior-posterior shift during maturation (Rivera et al., 2005). They concluded that practice and experience help to integrate negative numbers into an extended mental number line. In addition, Young and Booth (2015) found results both in line with an extended MNL and in line with a rulebased MNL account in two pointing experiments with middle school students. The authors concluded that this conflicting pattern could reflect under-developed number knowledge and differences in previous number exposure. In summary, previous findings in adult and children studies are highly controversial.

\section{REFERENCES}

Blair, K. P., Rosenberg-Lee, M., Tsang, J. M., Schwartz, D. L., and Menon, V. (2012). Beyond natural numbers: negative number representation in parietal cortex. Hum. Neurosci. 6, 1-17. doi: 10.3389/fnhum.2012.00007

Chassy, P., and Grodd, W. (2012). Comparison of quantities: core and formatdependent regions as revealed by fMRI. Cereb. Cortex 22, 1420-1430. doi: 10.1093/cercor/bhr219

Dehaene, S., Bossini, S., and Giraux, P. (1993). The mental representation of parity and number magnitude. J. Exper. Psychol. 122, 371-396. doi: 10.1037/0096-3445.122.3.371

Dodd, M. D. (2011). Negative numbers eliminate, but do not reverse, the attentional SNARC effect. Psychol. Res. 75, 2-9. doi: 10.1007/s00426-010-0283-6

Fischer, M. H. (2003). Cognitive representation of negative numbers. Psychol. Sci. 14, 278-282. doi: 10.1111/1467-9280.03435

Fischer, M. H., and Rottmann, J. (2005). Do negative numbers have a place on the mental number line? Psychology Science 47, 22-32.
The lack of consistent effects in adults does not provide a sufficient basis for firm developmental interpretations, thus distorting current conclusions about the development of negative number processing.

\section{METHODOLOGICAL COMMENT}

We believe that this ongoing debate benefits from a methodological comment. Specifically, we note that all published studies on negative number processing either presented spatially distributed stimuli or recorded response speed with lateralized keys (see Table 1). This use of spatially distributed stimuli or responses permits participants different strategies (e.g., selective attending to the sign or "mirroring" cf. Varma and Schwartz, 2011) and induces extraneous biases (e.g., the semantic congruity effect), all of which contaminates number processing (Fischer and Rottmann, 2005; Shaki and Petrusic, 2005; Gevers et al., 2010; Fischer and Shaki, 2016).

To address this concern, we recently developed a method where positive and negative numbers are interleaved with spatially oriented objects. Participants only ever see a single stimulus (number or object) and respond with a single button only if the relevant part of a conjunction rule was fulfilled (Fischer and Shaki, 2017). Examples are "respond only if the number is larger than -5 or the car is facing left" (incongruent rule) or "respond only if the number is smaller than -5 or the car is facing left" (congruent rule). We found that negative numbers are associated with space according to their signed magnitude, thus resolving the long-standing debate about the cognitive representation of negative numbers (Fischer, 2003; Shaki and Petrusic, 2005): Once the task prevents strategies, an extended mental number line prevails. This conclusion is based on results from a paradigm free of spatial or reporting biases. It can, in turn, inform our studies of the development of negative number concepts (Shaki and Fischer, 2018).

\section{AUTHOR CONTRIBUTIONS}

All authors listed have made a substantial, direct and intellectual contribution to the work, and approved it for publication.

Fischer, M. H., and Shaki, S. (2014). Spatial associations in numerical cognitionFrom single digits to arithmetic. Q. J. Exper. Psychol. 67, 1461-1483. doi: 10.1080/17470218.2014.927515

Fischer, M. H., and Shaki, S. (2016). Measuring spatial-numerical associations: evidence for a purely conceptual link. Psychol. Res. 80, 109-112. doi: 10.1007/s00426-015-0646-0

Fischer, M. H., and Shaki, S. (2017). Implicit spatial-numerical associations: negative numbers and the role of counting direction. J. Exp. Psychol. 43, 639-643. doi: 10.1037/xhp0000369

Ganor-Stern, D. (2012). Fractions but not negative numbers are represented on the mental number line. Acty Psychol. 139, 350-357. doi: 10.1016/j.actpsy.2011.11.008

Ganor-Stern, D., Pinhas, M., Kallai, A., and Tzelgov, J. (2010). Holistic representation of negative numbers is formed when needed for the task. Q. J. Exp. Psychol. 63, 1969-1981. doi: 10.1080/17470211003721667

Ganor-Stern, D., and Tzelgov, J. (2008). Negative numbers are generated in the mind. Exp. Psychol. 55, 157-163. doi: 10.1027/1618-3169. 55.3 .157 
Gevers, W., Santens, S., Dhooge, E., Chen, Q., Van den Bossche, L., Fias, W., et al. (2010). Verbal-spatial and visuospatial coding of number-space interactions. J.Exper. Psychol. 139, 180. doi: 10.1037/a0017688

Gullick, M. M., and Wolford, G. (2013). Understanding less than nothing: children's neural response to negative numbers shifts across age and accuracy. Front. Psychol. 4, 1-17. doi: 10.3389/fpsyg.2013.00584

Gullick, M. M., Wolford, G., and Temple, E. (2012). Understanding less than nothing: neural distance effects for negative numbers. Neuroimage 62, 542-554. doi: 10.1016/j.neuroimage.2012.04.058

Holyoak, K. J. (1978). Comparative judgments with numerical reference points. Cogn. Psychol. 10, 203-243. doi: 10.1016/0010-0285(78)90014-2

Huber, S., Cornelsen, S., Moeller, K., and Nuerk, H. C. (2015). Toward a model framework of generalized parallel componential processing of multi-symbol numbers. J. Exp. Psychol. Learn. Mem. Cogn. 41, 732-745. doi: 10.1037/ $\mathrm{xlm} 0000043$

Kong, F., Zhao, J., and You, X. (2012). Components representation of negative numbers: evidence from auditory stimuli detection and number classification tasks. Q. J. Exper. Psychol. 65, 691-701. doi: 10.1080/17470218.2011. 622048

Krajcsi, A., and Igács, J. (2010). Processing negative numbers by transforming negatives to positive range and by sign shortcut. Eur. J. Cog. Psychol. 22, 1021-1038. doi: 10.1080/09541440903211113

Loftus, A. M., Nicholls, M. E., Mattingley, J. B., Chapman, H. L., and Bradshaw, J. L. (2009). Pseudoneglect for the bisection of mental number lines. Q. J. Exp. Psychol. 62, 925-945. doi: 10.1080/17470210802305318

Nuerk, H. C., Iversen, W., and Willmes, K. (2004). Notational modulation of the SNARC and the MARC (linguistic markedness of response codes) effect. Q. J. Exp. Psychol. Sect. A 57, 835-863. doi: 10.1080/02724980343 000512

Parnes, M., Berger, A., and Tzelgov, J. (2012). Brain representations of negative numbers. Can. J. Exper. Psychol. 66:251. doi: 10.1037/a0028989

Prather, R. W., and Boroditsky, L. (2003, January). "Left of zero: Representing negative numbers on the mental number line," in 25th Annual Meeting of the Cognitive Science Society (Boston, MA).
Rivera, S. M., Reiss, A. L., Eckert, M. A., and Menon, V. (2005). Developmental changes in mental arithmetic: evidence for increased functional specialization in the left inferior parietal cortex. Cereb. Cortex 15, 1779-1790. doi: 10.1093/cercor/bhi055

Shaki, S., and Fischer, M. H. (2018). Deconstructing spatial-numerical associations. Cognition.

Shaki, S., and Petrusic, W. M. (2005). On the mental representation of negative numbers: context-dependent SNARC effects with comparative judgments. Psychonomic Bull. Rev. 12, 931-937. doi: 10.3758/BF03196788

Tse, C. S., and Altarriba, J. (2010). The revelation of the negative side of a mental number line depends on list context: evidence from a sign priming paradigm. Eur. J. Cogn. Psychol. 22, 1248-1260. doi: 10.1080/09541440903427495

Tzelgov, J., Ganor-Stern, D., and Maymon-Schreiber, K. (2009). The representation of negative numbers: exploring the effects of mode of processing and notation. Q. J. Exp. Psychol. 62, 605-624. doi: 10.1080/17470210802034751

Varma, S., and Schwartz, D. L. (2011). The mental representation of integers: an abstract-to-concrete shift in the understanding of mathematical concepts. Cognition 121, 363-385. doi: 10.1016/j.cognition.2011.08.005

Young, L. K., and Booth, J. L. (2015). Student magnitude knowledge of negative numbers. J. Num. Cogn. 1, 38-55. doi: 10.5964/jnc.v1i1.7

Zhang, Y. and You, X. (2012). Extending the mental number line-How do negative numbers contribute?. Perception 41, 1323-1335. doi: 10.1068/p7081

Conflict of Interest Statement: The authors declare that the research was conducted in the absence of any commercial or financial relationships that could be construed as a potential conflict of interest.

Copyright (c) 2018 Mende, Shaki and Fischer. This is an open-access article distributed under the terms of the Creative Commons Attribution License (CC $B Y)$. The use, distribution or reproduction in other forums is permitted, provided the original author(s) and the copyright owner are credited and that the original publication in this journal is cited, in accordance with accepted academic practice. No use, distribution or reproduction is permitted which does not comply with these terms. 